\title{
LA TÉCNICA Y EL NATURALISMO METODOLÓGICO
}

\author{
Álvaro Monterroza ${ }^{1}$
}

\section{Resumen}

El artículo reseña y reconstruye algunas reflexiones sobre la naturaleza de la técnica para mostrar que ésta no es sólo una estrategia evolutiva ligada a la supervivencia como el resto de animales, sino como moldeadora del ser humano en su integridad. Adopto una postura naturalista flexible (naturalismo metodológico) en la que se acepta la complementariedad de la filosofía con las ciencias naturales y la favorabilidad de ésta para el estudio filosófico de la técnica. Aunque en un principio se puede pensar que las reflexiones sobre la técnica desde la tradición filosófica como las de Ortega y Gasset y las de Heidegger son distantes y excluyentes de las tesis de algunos filósofos naturalistas, se muestra que esta distinción es difusa y que, por el contrario, se pueden complementar, si se asume un naturalismo como el que adoptamos.

\section{Palabras clave}

Técnica, naturalismo, naturalismo metodológico, evolucionismo.

1 Magíster en Ingeniería, ingeniero químico y estudiante de filosofía. Actualmente se desempeña como docente e investigador del INSTITUTO TECNOLÓGICO METROPOLITANO de Medellín en el grupo de investigación CTS. alvaromonterroza@ itm.edu.co 


\section{Alostract}

This article highlight and reconstructs some reflexions on the nature of technique to show that this is not only an evolutionary strategy tie to the survival, as in the case of other animals, but something that molds the human being as a whole. I adopt a flexible naturalist approach (methodological naturalism) in which philosophy is accepted as being complementary to the natural sciences and as well-suited for the philosophical study of technique. Although it could initially be supposed that reflexions on technique taken from philosophical tradition, such as those of Ortega y Gasset and of Heidegger, both of them are distant and mutually exclusive, it is shown that this distinction is diffuse and that, to the contrary, they may complement each other if one adopts a naturalist approach such as this one.

\section{Key words}

Technique, naturalism, methodological naturalism, evolutionism. 


\section{INTRODUCCIÓN}

La técnica es considerada, en general, como ese conjunto de normas, reglas y procedimientos para obtener un resultado. Los

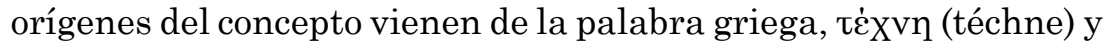
lo más común es asociar a la técnica con los artefactos, pero también se incluyen las habilidades para llevar a cabo un proceso productivo, artístico o social. Esta descripción, típica de una enciclopedia, es muy general y se requiere de un estudio más profundo, que tenga en cuenta los puntos de vista de las diversas disciplinas (antropología, sociología, historia, ciencias naturales y filosofía) para acercarse a una definición más satisfactoria. De hecho, la técnica en sí misma es un objeto de estudio filosófico.

En este artículo presentaremos inicialmente qué se entiende por técnica desde la antropología y desde algunas filosofías naturalistas como la de Agazzi o la de García Palacios; posteriormente, mostraremos los límites de sus resultados y ahondaremos en la distinción entre la técnica de algunas especies vivas y la técnica humana.

Se enriquecerá el concepto de técnica con las ideas de Julián Pacho, Leroi-Gourhan y Ortega y Gasset, para mostrar que la técnica no se limita a la supervivencia, sino que constituye un factor de emancipación del ser humano.

Al final, se retomará la postura naturalista, para mostrar que las reflexiones de tipo metafísico como las de Ortega y Heidegger no son contrarias al naturalismo y que, por el contrario, se basan en los mismos supuestos naturalistas de otros filósofos.

\section{LA TÉCNICA ENTENDIDA POR LA ANTROPOLOGÍA Y EL EVOLUCIONISMO}

Una típica definición de técnica es la del filósofo italiano Evandro Agazzi: un conjunto de conocimientos eficaces que el hombre ha desarrollado a lo largo de los siglos para mejorar su manera de vivir prácticamente. Consecuencia de esto, la técnica se concibe 
como un saber tan antiguo como la humanidad misma y, desde el punto de vista de la antropología filosófica, se comprende como una característica específica del hombre, puesto que, si se considera que los animales sobreviven adaptándose al medio ambiente, el hombre, en cambio, sobrevive adaptando el medio ambiente a sí mismo (Agazzi, 1997).

Esta definición de Agazzi es un lugar común entre muchos filósofos de corte naturalista ${ }^{2}$. Sin embargo, desde otro punto de vista, puede considerársela como una definición simplicadora y antropocentrista. En efecto, se le puede replicar que las construcciones de algunos invertebrados como hormigueros, panales, o las de algunos vertebrados como nidos o presas también son modificaciones del medio a favor de las especies mismas. Como la especie humana, muchas especies animales también han cambiado su estrategia evolutiva. Sin embargo, aplazaremos un poco la respuesta a esta réplica y, por ahora, resaltaremos algunas observaciones de la antropología acerca del origen de la técnica.

Si la técnica es tan antigua como el hombre mismo, desde una postura filosófica naturalista, ${ }^{3}$ creo conveniente, en primer lugar, evocar las teorías del origen del hombre surgidas en la antropología, ya que es un buen punto de partida para estudiar el concepto de técnica y la razón de su importancia en la constitución del ser humano.

La antropología ha lanzado diversas hipótesis de cómo surgió el proceso de hominización, es decir, los procesos biológicos por medio de los cuales a partir de algunos primates surgieron los humanos. Los antropólogos no han llegado a acuerdos definitivos sobre la importancia y orden de esos factores determinantes en la hominización, pero sí se identifican algunos que influyen sobremanera

2 Es importante anotar que esta afirmación se aplica solamente a un sector de los naturalistas, ya que esta postura filosófica es muy amplia y tiene muchos matices.

3 La postura filosófica naturalista afirma, además que los resultados de las ciencias son un buen material de trabajo para la actividad filosófica, ergo, la filosofía no es una actividad prescriptiva a priori, sino que también es reflexiva a posteriori. 
como el de la sociabilidad, el de la capacidad lingüística y el de las habilidades técnicas. La permanente e intensa interacción social de los homínidos fue una condición que ayudó a que surgiera un cambio de hábitat que marcó la transición de una vida arborícola a la caza en cooperación. Sin embargo, según García Palacios, fue la posición vertical el primer criterio de humanidad que liga a los hombres con sus antepasados (García Palacios, 2005, p. 35). Como derivaciones de esto, surgió la posesión de cara corta, la desaparición de caninos ofensivos y las manos liberadas de la locomoción, lo cual, en consecuencia, permitió la posesión y manipulación de útiles como primera condición para el desarrollo de técnicas en las que el cerebro jugará un papel integrador (García Palacios, Ibid.).

Nuestra especie ha establecido una diferencia evolutiva al aumentar su capacidad cerebral. La bipedación liberó sus manos para emplearlas en instrumentos que potencian y desarrollan las facultades mentales hasta la aparición del lenguaje y la inteligencia. A partir de ahí, lo heredado - unos cien mil genes- queda disminuido ante el potencial del cerebro: más de 10.000 millones de neuronas en compleja conexión sináptica (Bernabeu Rico, 1997, p. 17). De esta hiperformalización de la mente ${ }^{4}$ (que produce o producida por? la educación cultural) procede, según Bernabeu Rico "la gran plasticidad del hombre, que posibilita una gran pluralidad de direcciones en el comportamiento" (Bernabeu Rico, 1997, p. 18).

Ahora bien, si indagamos más en los detalles de los mecanismos que propone la antropología, ésta nos señala que el cambio de arborícolas a cazadores sociales tuvo que estar acompañado necesariamente de una capacidad comunicativa superior a la de cualquier otro mamífero. Pero esto sólo fue posible porque estos monos arborícolas, sin grandes garras y con escasa fuerza física, usaron sus manos hábilmente para lanzar piedras o palos, para cazar sus presas o para defenderse de sus depredadores. Así, estos

Podríamos afirmar que la hiperformalización es del cerebro en concreto en vez de la mente, sin embargo no tomaré postura frente al problema mente-cerebro. 
instrumentos pequeños, que con el tiempo se convirtieron en objetos más sofisticados (mazos, lanzas, cuchillos punzones), fueron los que lograron dar una ventaja biológica sobre otros depredadores mejor dotados biológicamente (García Palacios, 2005, p. 36).

En vista de este cambio en la estrategia biológica, que marcó la aparición de prácticas de modificación del entorno a partir de actos y gestos técnicos, superadoras de las coerciones naturales de la evolución biológica, las variaciones anatómicas adaptativas dejaron de afectar radicalmente al Homo sapiens. ${ }^{5}$ La evolución de la especie humana se volvió más cultural que natural y comenzó a verse potenciada por la innovación en hallar cada vez mejores y más variadas soluciones a los problemas mediante la sofisticación de los artefactos y los gestos y actos técnicos (García Palacios, Ibid.). Por mencionar algunos actos técnicos señalamos la domesticación del fuego, la cocción de alimentos, la domesticación de animales, la agricultura, el vestido, la cerámica, la pesca, la construcción de viviendas, entre muchos otros.

Sin embargo, aún no se responde a la pregunta de por qué la técnica humana es distinta de la técnica de las demás especies; no se resuelve todavía la pregunta de por qué los actos técnicos humanos no se limitan sólo a la supervivencia.

\section{LA TÉCNICA NO SE LIMITA A LA SUPERVIVENCIA}

¿Qué pasa con las otras especies que también tienen comportamiento técnico, al ser tan evidentes las diferencias entre sus producciones técnicas y las de los humanos? ¿Qué relación se establece entonces entre el gesto técnico y la racionalidad? ¿Qué es lo que diferencia la técnica de algunas especies y la técnica humana?

5 No quiere decir esto que los cambios biológicos del humano se asumen como una especie de mutación total e intempestiva debida a la aparición de la técnica, pero sí se puede afirmar que su intensidad disminuyó en la medida en que las prótesis técnicas lograron satisfacer las necesidades del hombre como especie. 
Para responder a estas preguntas recurrimos a la tesis de Julián Pacho, quien hace una distinción entre técnica y "razón técnica". La técnica es la "capacidad de creación y aplicación de instrumentos autocorregibles" (Pacho, 1997, p. 59). Por lo tanto, la técnica humana no se puede reducir a los actos técnicos de otras especies (construcción de nidos, presas o madrigueras, por ejemplo), sino que está mediada por lo que Pacho denomina la "razón técnica" y el "sistema de hipótesis sobre sí mismo y sobre su entorno, aplicable a ambos y perfectible, perfectible por sí mismo" (Pacho, Ibíd.).

La técnica humana está mediada por la razón técnica, esa racionalidad para construir artefactos como manifestación externa en la que se plasma el imaginario humano. Es perfectible en la medida en que puede mejorarse, autocorregirse. Es necesario imaginar la finalidad del instrumento, su función, su forma de usarlo, para así tratar de construirlo, es decir, usar la racionalidad (técnica). Otra característica de la razón técnica es su flexibilidad: no se elaboran los mismos instrumentos en forma automática, sino que se adaptan y se adoptan innovaciones de acuerdo a las necesidades. Así, la técnica humana está condicionada por los recursos materiales disponibles, la tradición cultural del grupo social y las aspiraciones del individuo. En tanto que es perfectible, se puede repensar, modificar, perfeccionar, se puede transmitir a las próximas generaciones que continuarán acabándola sin que parezca llegar a un estado de perfección absoluta.

¿Acaso esta noción de autocorrección no es aplicable a otras especies? Hay que responder negativamente, pues, por ejemplo, los hormigueros o los panales (como productos de actos técnicos) no poseen ni la plasticidad, ni la diversidad, ni la innovación evidentes en los actos técnicos humanos. No obstante, para dar un argumento más sólido, se puede recurrir a las teorías del etno-paleontólogo francés André Leroi-Gourhan que explican la naturaleza de la técnica humana y su diferencia con la técnica de otras especies.

Esta diferencia se puede plantear con la distinción entre inteligencia e instinto. Si tanto para los humanos como para todo el mundo zoológico se puede hablar de componentes de 
inteligencia y componentes de instinto, es sabido por la etología que los vertebrados superiores (primates y cazadores) tienen un componente de inteligencia más alto que el que pueden tener los invertebrados. Leroi-Gourhan afirma que frente al instinto y la inteligencia las especies animales podrían agruparse en tres tipos. El primero es el de los invertebrados inferiores, con un sistema cerebral muy elemental, en el que los programas se constituyen a partir de cadenas operatorias ${ }^{6}$ cortas y de actos muy sencillos, que se activan con la interacción con el medio (Leroi-Gourhan, 1971, p. 218). El autor señala que en animales como lombrices, babosas, etc., la memoria es comparable a la de una máquina electrónica que reaccionan con estímulos automáticos entre sus necesidades internas y las constricciones de su medio. El segundo tipo, es el de los invertebrados con estructuras de organización más complejas como las hormigas, las abejas o las termitas. Estos animales, aparentemente, tienen programas complejos de comportamiento inscritos genéticamente, pero a pesar de lo aparentemente diverso, no admiten más que un escogimiento mínimo de respuestas. El tercer tipo, afirma Leroi-Gourhan, sería el de los vertebrados, en los cuales gran parte de su comportamiento está basado en las funciones automáticas entre las pulsiones fisiológicas y las solicitudes del medio externo, del mismo modo que los invertebrados, pero adicionalmente cuentan con un componente flexible de las cadenas de comportamiento, principalmente en los vertebrados mayores como los mamíferos y las aves, es decir, tienen más posibilidades de opción entre las cadenas operatorias. Para explicar esto, LeroiGourhan retoma el paralelismo con las máquinas electrónicas a las que habría que agregar, además del sistema de conexiones y de

6 El concepto de cadena operativa (chaîne opératoire) de André Leroi-Gourhan define el conjunto de pasos encadenados (secuencia dinámica) que se dan en la producción de artefactos líticos, desde la recogida de la materia prima, hasta su abandono, pasando por las diferentes fases de fabricación (generalmente la talla), de su utilización y de su reconstrucción (afilado, reavivado, reaprovechamiento...) y su reutilización, si se diera el caso. Las cadenas operativas permiten establecer diferentes estilos y estrategias culturales, por lo que son una herramienta conceptual de inestimable valor en prehistoria y arqueología. 
memoria, un sistema de conexiones suplementarias en las que se presentarían confrontaciones productoras de una gran diversidad respuestas (Leroi-Gourhan, 1971, p. 220).

¿Y cómo ayuda esto a distinguir entre la técnica humana y la técnica de las abejas u hormigas? La posible respuesta de LeroiGourhan se orienta por la vía de la caracterización del cerebro humano como un aparato de confrontaciones que permite, en primer lugar, la inscripción en la memoria de numerosas cadenas operatorias y también la libertad de operación entre las cadenas. Esto corresponde, según Leroi-Gourhan, a la inteligencia. Los grados de libertad del comportamiento técnico ya no se realizan, como en otras especies, en los actos, sino en el nivel de los procesos de simbolización, y la representación simbólica de los actos es indisociable de su confrontación (Leroi-Gourhan, 1971, p. 222). Aquí observamos que la toma de decisiones, el paso al acto, en el humano, es una función reflexiva y no un mecanismo de adaptación biológica y que esta función, como afirma Leroi-Gourhan, sólo puede ser simbólica, es decir, estrechamente ligada al lenguaje. Esto nos lleva a señalar las diferencias significativas entre la técnica humana y la de otras especies.

Uno de los hallazgos más importantes de André Leroi-Gourhan, es el de haber advertido que las confrontaciones entre diferentes cadenas operatorias en el humano permiten la reparación, la mejora y la innovación, tanto en el dominio de las relaciones sociales, como en las técnicas. Dice Leroi-Gourhan, "lo propio de las sociedades humanas es acumular las innovaciones técnicas y conservarlas, lo cual está ligado a la memoria colectiva, mientras que depende del individuo organizar sus cadenas operatorias, conscientemente, hacia la fijación de procesos operativos nuevos..." (Leroi-Gourhan, 1971, p. 229).

Aquí vemos la más importante diferencia entre la técnica humana y la animal, la posibilidad de conservar y transmitir, desde y por fuera del cuerpo, información, en la memoria colectiva, a través del lenguaje, y no sólo a través de los genes. Los individuos humanos podemos, gracias a ello, partir de ese punto hacia la 
formulación de reparaciones, innovaciones y mejoras. Entonces, a diferencia de las aves o de las hormigas, el Homo sapiens es un ser técnico innovador atravesado por el lenguaje, el cual le permite almacenar la memoria colectiva y a la vez confrontar las cadenas operatorias. Por lo tanto, la técnica humana está mediada por una racionalidad humana técnica. Esto trae consecuencias importantes: si la técnica está mediada por la razón y por la complejidad de sus elementos mentales e intencionales, no se debe limitar solamente a cuestiones de supervivencia.

Para reafirmar que la técnica no se desarrolla sólo a partir de necesidades biológicas, cito las reflexiones de José Ortega y Gasset en su ensayo Meditación de la técnica (1939)(reeditado en 1982), quien afirma que, con la técnica, no se pretende sólo satisfacer las necesidades básicas de la vida, no se busca sólo sobrevivir, sino vivir bien. El principal objeto del surgimiento de la técnica es más el bienestar que el propio vivir: “... se deduce que el empeño del hombre por vivir, por estar en el mundo, es inseparable de su empeño en estar bien... el bienestar y no el estar es la necesidad fundamental para el hombre, la necesidad de las necesidades" (Ortega, 1982, p. 33). Para Ortega, en el hombre, el bienestar prima sobre la necesidad biológica, debido a que la vida humana se entiende como un camino de infinitas posibilidades de realización de proyectos, como un plan que habla desde un futuro al presente al cual fundamenta y llena de sentido, pero por sobre todo como algo problemático y difícil. El ser humano parece ser el único ser que nace "incompleto", en el sentido de que permanentemente está visualizando o fantaseando cómo se vería en un futuro; el animal, aunque tiene propósitos (biológicos de alimento, reproducción y supervivencia) no se visualiza a sí mismo, ni su situación ante el mundo y, consecuentemente, no prevé su futuro como ser. En consecuencia, la vida humana es precisamente todo lo que no hace el animal, es todo el conjunto de actos, gestos y comportamientos realizado más allá del propósito de sostenerse biológicamente en la naturaleza. En palabras de Ortega: 
... el hombre tiene una tarea muy distinta a la del animal, una tarea extranatural, no puede dedicar sus energías como aquel a satisfacer sus necesidades elementales, sino que, desde luego, tiene que ahorrarlas en ese orden para poder vacar ${ }^{7}$, con ellas, a la improbable faena de realizar su ser en el mundo. (Ortega, 1982, p. 53).

Esto se da porque el ser humano parece haber nacido para: "esforzarse en que haya lo que aún no hay; a saber, el mismo, aprovechando para ello lo que hay; en suma es producción" (Ortega, 1982 , p. 55). En su conferencia "El mito del hombre allende la técnica"8 (Darmstadt, 1951), Ortega y Gasset expuso un mito en el cual un animal, a causa de una anomalía biológica, desarrolló una capacidad de memoria de largo plazo, que lo distinguió fuertemente de sus congéneres. Como podía mantener nítidos y completos los recuerdos de sus vivencias, podía retrotraerlos en todo momento, es decir, podía revivir lo vivido. Al poder almacenar los recuerdos, este animal "se convirtió en el primer hombre que había encontrado súbitamente una enorme riqueza de figuras imaginarias en sí mismo" (Ortega, 2001, p. 137). Ese animal, dice Ortega, era una anomalía, estaba loco, lleno de fantasía como ninguno. A diferencia de los otros, tenía otro mundo: un mundo interno para sí mismo. Los demás seres están volcados todo el tiempo hacia fuera (al mundo exterior), hacia su relación con el entorno y su supervivencia, pero este anómalo tiene la oportunidad de regresar hacia sí mismo, de visualizar no sólo las cosas como "son" sino cómo "podrían ser". Con su mundo interior, este animal puede imaginar cómo intervenir las realidades, es decir, desplegar actos técnicos, lograr más grados de libertad y no solamente reaccionar ante los estímulos del medio y las necesidades biológicas.

7 Descansar, cesar, holgar.

8 Esta conferencia se ha recogido en diferentes publicaciones. Yo recojo la compilación de López Cerezo, Luján y García Palacios hecha sobre Filosofía de la Tecnología para la colección Temas de Iberoamérica para la Organización de Estados Iberoamericanos [2001]. 
Lo anterior muestra que la técnica humana no es instintiva, está liberada por y para la voluntad y el libre albedrío, está mediada por una intención voluntaria en concordancia con la conciencia del individuo: conciencia de si, del entorno y de los otros. Por otro lado, la técnica es la que permite la emancipación y los espacios para regresar al mundo interior (de imaginaciones y pensamientos); al emanciparnos de las penurias naturales, potenció el raciocinio humano con el que podemos fantasear y proyectar nuestra existencia. De hecho, el filósofo francés Michel Onfray señala a la técnica como "el conjunto de medios empleados por los hombres para emanciparse de las necesidades y penalidades naturales" (Onfray, 2005, p. 99). Una vez más, la técnica no se limita a la supervivencia.

\section{El naturalismo no limita la técnica a la supervivencia}

A diferencia de lo que podría creerse, se puede hablar de naturalismo como de una postura tradicional de la filosofía, ya que, desde el siglo XVII, existían filósofos naturalistas que buscaban describir las causas de fenómenos físicos, humanos y morales, sin recurrir a la intervención de agentes sobrenaturales. Existe una extensa historia de lo que se conoce como naturalismo y de cómo éste puede intervenir en dimensiones humanas y naturales, pero contarla nos desviaría del objetivo modesto del presente artículo.

Aquí interesa más bien llamar la atención sobre el naturalismo cognitivo, más precisamente, la corriente surgida en la segunda mitad del siglo XX con la aparición del texto clásico de Quine, "Naturalización de la Epistemología", en el cual el autor propone una apropiación de los resultados de las ciencias cognitivas como la psicología para estudiar la diversidad de reacciones del sujeto (sus procesos fisiológicos o psíquicos) frente a los estímulos y concebir así una epistemología, en íntima relación con la psicología, y que acometa la tarea de estudiar las relaciones entre teoría y evidencia. A raíz de esta propuesta, se han planteado diversas tesis que aceptan de forma total o parcial la propuesta de Quine. 
La filósofa Diana Pérez ha hecho una reconstrucción de las diversas propuestas surgidas. La autora muestra que el naturalismo puede comprenderse en dos sentidos principales, no necesariamente incompatibles.

La primera tesis, la tesis epistemológica, afirma que la ciencia y la filosofía se relacionan de manera tal que forman un continuo. Esta tesis del naturalismo epistemológico del primer sentido afirma que la ciencia y la filosofía comparten sus objetos de estudio. Llevada al extremo, la ciencia y la filosofía comparten, además de sus objetos, sus métodos y sus cánones de justificación y es ésta la tesis del naturalismo epistemológico del segundo sentido. Desde nuestra postura, esta última tesis implica la eliminación de la dimensión filosófica de la epistemología. ${ }^{9}$. Sin embargo, de cualquier forma, si se acepta la posición naturalista cognitiva, pierde sentido una filosofía primera normativa (fundacionalista) y se impone una filosofía descriptiva.

La segunda tesis naturalista es ontológica: todo lo que existe es natural. Por eso las entidades naturales y sus relaciones forman parte de un sistema espacio-temporal causalmente cerrado. Como consecuencia, todo lo que existe es natural, ya que, si se lograra demostrar la existencia de alguna entidad sobrenatural, sería gracias a causas naturales. Esto podría llevar al fisicalismo ${ }^{10}$, puesto que esta tesis ontológica es demasiado explicativa como para aceptarla con todas sus consecuencias.

Del naturalismo aceptamos tomar su tesis epistemológica en el primer sentido, según el cual la filosofía y la ciencia forman un continuo, pero sólo en cuanto a su objeto de estudio y a esta postura la llamaremos naturalismo metodológico. Al segundo

9 Que la filosofía debe volverse parte de la ciencias, es la tesis que llamo "el segundo sentido" y he presentado en otro lugar una réplica debatiéndola: véase Monterroza, 2007.

10 Por fisicalismo se entiende esa postura (filosófica y científica) que afirma que todo lo que existe está constituido por entes físicos y por la interacción entre entes físicos. Afirma que lo sobrenatural no existe (no es real) y que si se demostrara su existencia, sería gracias a un fenómeno también natural. 
sentido del naturalismo, lo llamaremos naturalismo metafísico o tesis ontológica. $\mathrm{Y}$ definitivamente no nos comprometemos con esta segunda tesis, puesto que nos parece indemostrable en términos formales y con evidencias que todo lo que existe es natural. Por mucho que la ciencia pueda un día explicar fenómenos sobrenaturales, no por eso quedaría demostrado que lo haga de una vez por todas. El naturalismo metodológico (que adopto) suspende el juicio en cuanto a lo sobrenatural. Considera que el medio natural debe ser estudiado por las ciencias naturales y que ese estudio y sus resultados plantean problemas y preguntas a la filosofía y enriquece tesis, conceptos y teorías filosóficas.

Caseres señala una diferencia entre el naturalismo más tradicional, el metafísico, y las reflexiones filosóficas (metafísicas) sobre la técnica. Ortega y Heidegger (La pregunta por la técnica, 1986), muestran que existe una gran afinidad entre el humanismo y la técnica, como también la imposibilidad de definir "técnicamente" la técnica a partir de su propio desarrollo, y tienden a sospechar de su supuesta neutralidad y de su carácter de aplicación. Por su parte, Ortega considera la técnica como un medio instrumental que define una antropología característica o específica de unos fines. Heidegger plantea la técnica como una ventana más del pozo del ser, como un elemento o actividad más a partir del cual el ser humano desvela una verdad general (Casares, 2000, p. 6), es decir, "desoculta" la fuerza de la naturaleza.

Según Casares, para Heidegger y para Ortega y Gasset, la técnica es la resuelta expresión que supone una proyección "no natural" del hombre en el mundo. La técnica constituye una ruptura radical con el orden orgánico y natural. Existe una marcada y significativa diferencia entre lo "artificial" y lo "natural" y, en ella, la técnica se inscribe fundamentalmente en lo "artificial".

Casares muestra ambas concepciones en la siguiente figura, que intenta aclarar por qué parecen incomunicables. 




Figura 1. Concepciones del hombre en LA NATURALEZA CON LA TÉCNICA DESDE LO ARTIFICIAL Y LO NATURAL (BASADO EN CASARES, 2008)

La visión "natural" que muestra Casares (figura 1: Hombre C Naturaleza) no es propia del naturalismo metodológico, pues muestra al hombre como elemento del mundo natural, pero señala que la técnica es sólo una estrategia evolutiva.

\section{El naturalismo es favorable para eStudiar la téCNicA}

A pesar de que la técnica humana no se limita a la supervivencia ¿por qué es favorable una posición naturalista metodológica para hacer filosofía de la técnica? Para responder a esta pregunta tomaremos la tesis de la imagen natural del mundo del filósofo vasco Julián Pacho, quien señala que las ciencias nos suministran teorías que llenan (parcialmente) las lagunas de nuestra limitada experiencia. Pacho considera que la imagen natural del mundo es la que se deriva del uso intuitivo de nuestro sistema cognitivo y que está, por tanto, determinada por las estructuras elementales de la experiencia y del lenguaje corrientes, dicho de otro modo es la imagen determinada por la experiencia y por la gramática del lenguaje corriente, la imagen no sometida al control de reglas o instancias críticas propuestas ad hoc. Si se conviene en llamar experiencia "natural" a este tipo de experiencia inmediata o corriente, no revisada mediante artificios teórico-experimentales y reflejada por el lenguaje corriente, entonces podría decirse que la imagen natural es la imagen que corresponde a la experiencia natural (Pacho, 1997a p 20). Es decir, hacer filosofía de la técnica 
sólo con meditaciones alimentadas por nuestra limitada experiencia cotidiana es más "natural" que el mismo naturalismo.

Otro ejemplo de naturalismo metodológico es el trabajo de André Leroi-Gourhan. Sus escritos denotan muchos componentes filosóficos, además de los propios de la profesión de paleontólogo. Leroi-Gourhan afirma: “... es, incluso, extremadamente sano, que la ciencia del ser humano sea la más interdisciplinar de todas las disciplinas" (Leroi-Gourhan, 1971).

Por otro lado, también se puede señalar como ejemplo, el de Ortega y Gasset: ¿cómo llegó este filósofo a expresar que las características de las especies animales no son acabadas, sino que son dinámicas y pueden mutar? Ortega muestra su afinidad con la teoría de la evolución, la misma que lo llevó a meditar sobre el primer protohombre que sufriera una anomalía y lograra tener memoria de sus experiencias, hecho que, según Ortega, pudo ser el primer paso para una racionalidad técnica. Asumir los resultados de las ciencias, según la postura del naturalismo metodológico, es válido y enriquecedor y no compite con las reflexiones metafísicas sobre la técnica (o sobre otros problemas filosóficos) elaboradas por filósofos tradicionales.

\section{Conclusiones}

La técnica humana es un comportamiento mediado por la racionalidad, es decir, existen elementos de libertad, inteligencia y reflexión mediados por el lenguaje, que marcan la distinción entre los actos técnicos humanos y los de otras especies animales.

Lo anterior trae como consecuencia que la técnica humana no sólo se limitó a la supervivencia, sino que posibilitó la emancipación de los humanos respecto a la naturaleza y, por ende, la emergencia del pensamiento, la imaginación, la proyección del futuro, el arte, la religión y todo lo que nos hace humanos.

El estudio filosófico de la técnica es pertinente en el programa del naturalismo (metodológico) en el cual se estudian y se asumen algunas teorías de las ciencias naturales (biología evolucionista, antropología física), pero no se descartan reflexiones filosóficas 
sobre la capacidad de la técnica de ser modeladora del ser humano. No ser naturalistas metodológicos, es decir, hacer filosofía desconociendo los resultados de las ciencias, es ser más "natural" que el mismo naturalismo (como afirma Julián Pacho). Al no contar con teorías mediadas por el control de reglas o instancias críticas (aportadas por las ciencias), quedan grandes lagunas en la experiencia, limitantes de la actividad filosófica de reflexión sobre la técnica. Por otro lado, si se suprime toda la filosofía (sus cánones de justificación, métodos argumentativos, sus contenidos, metateorías y reflexiones) se puede desembocar en un cientificismo ingenuo que no lograría poner en perspectiva los problemas de la naturaleza humana.

\section{Biblografía}

AGAZZI, Evandro (1997). Seminario: El Impacto Epistemológico de la Tecnología. Facultad de Filosofía de la Universidad de Sevilla. Sevilla. 7 y 8 de abril de 1997. Disponible en Dialnet.

BERNABEU RICO, José (1997). Educación y Dimensiones de las Educación. Parte de “Teorías e Instituciones Contemporáneas de la Educación”. Ed. Ariel, Barcelona. Compilación por Antoni Rico y otros.

CASARES SERRANO (2008), Antonio. Genes, Tecnología y Racionalidad. La estrategia naturalista en la unificación epistemológica de las ciencias. A Parte Rei, revista de Filosofía, documento“electrónico disponible en: [http://serbal.pntic.mec.es/ cmunoz11/casares39.pdf] consultado el 1 de junio de 2008.

GARCÍA PALACIOS, Eduardo Mariano (2005). ¿Qué es la Técnica? Parte de: Ciencia, tecnología y sociedad: una aproximación conceptual. España: Organización de Estados Iberoamericanos (OEI), Madrid.

HEIDEGGER, Martín (1986). La pregunta por la técnica. Revista Universidad de Antioquia Vol. 53, No. 205 (jul.-sep. 1986).

LEROI-GOURHAN, André (1971). El gesto y la palabra. Publicaciones de la Universidad Central de Venezuela, Caracas.

MONTERROZA, Álvaro (2007). La epistemología naturalizada y la necesidad de mantener su dimensión filosófica. Tecnológicas $\mathrm{N}^{\circ}$ 18. Dic. 2007.

ONFRAY, Michel (2005). Antimanual de Filosofía. Lecciones socráticas y alternativas. Edad Ensayo. Madrid. 
ORTEGA Y GASSET (1982), José. Meditación de la Técnica. Y otros ensayos sobre la ciencia y la filosofía. Revista de Occidente en Alianza Editorial. Madrid.

(1951). El Mito del Hombre Allende la Técnica. Parte de: Temas de Ibero América: Filosofía de la Tecnología. Organización de Estados Iberoamericanos para la Educación, la Ciencia y la Cultura (OEI), Madrid, 2001 pp. 136-140.

PACHO, Julián (1997). Los Nombres de la Razón. Ensayo sobre los conceptos de razón y naturaleza en la tradición occidental. Bilbao. Servicio editorial Universidad del País Vasco.

(1997 a). Las imágenes del mundo y el porvenir de la filosofía. Revista de filosofía, ISSN 0034-8244, № 18, 1997, págs. 17-39.

PÉREZ, Diana (comp.) (2002). Los caminos del naturalismo. Mente, conocimiento y moral. Buenos Aires.

QUINE, Willard van Orman. Relatividad ontológica. Madrid. Tecnos. 1974. 206 pág. Cap. 3.

WINNER, L. (1976). Tecnología Autónoma. Barcelona, Gustavo Gili, S.A. 1976. 